\title{
Solution Structure of Metal Particles Prepared in Unimolecular Reactors of Amphiphilic Hyperbranched Macromolecules
}

\author{
V. Garamus, T. Maksimova, W. Richtering*, L. Antonietti, \\ C. Aymonier, R. Thomann, S. Mecking*
}

Supporting Information

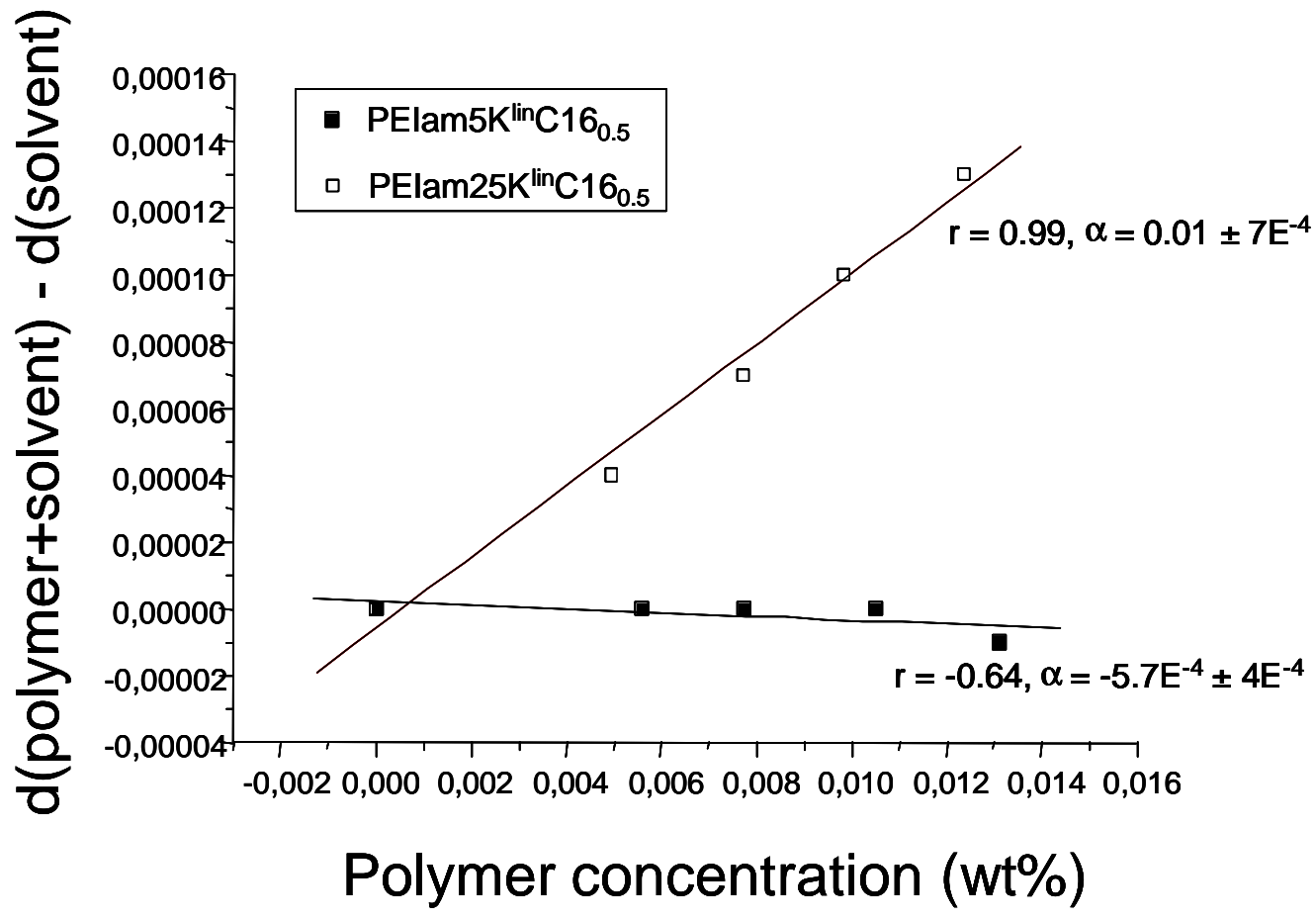

Figure S1. Density of polymer solutions at various concentrations. 

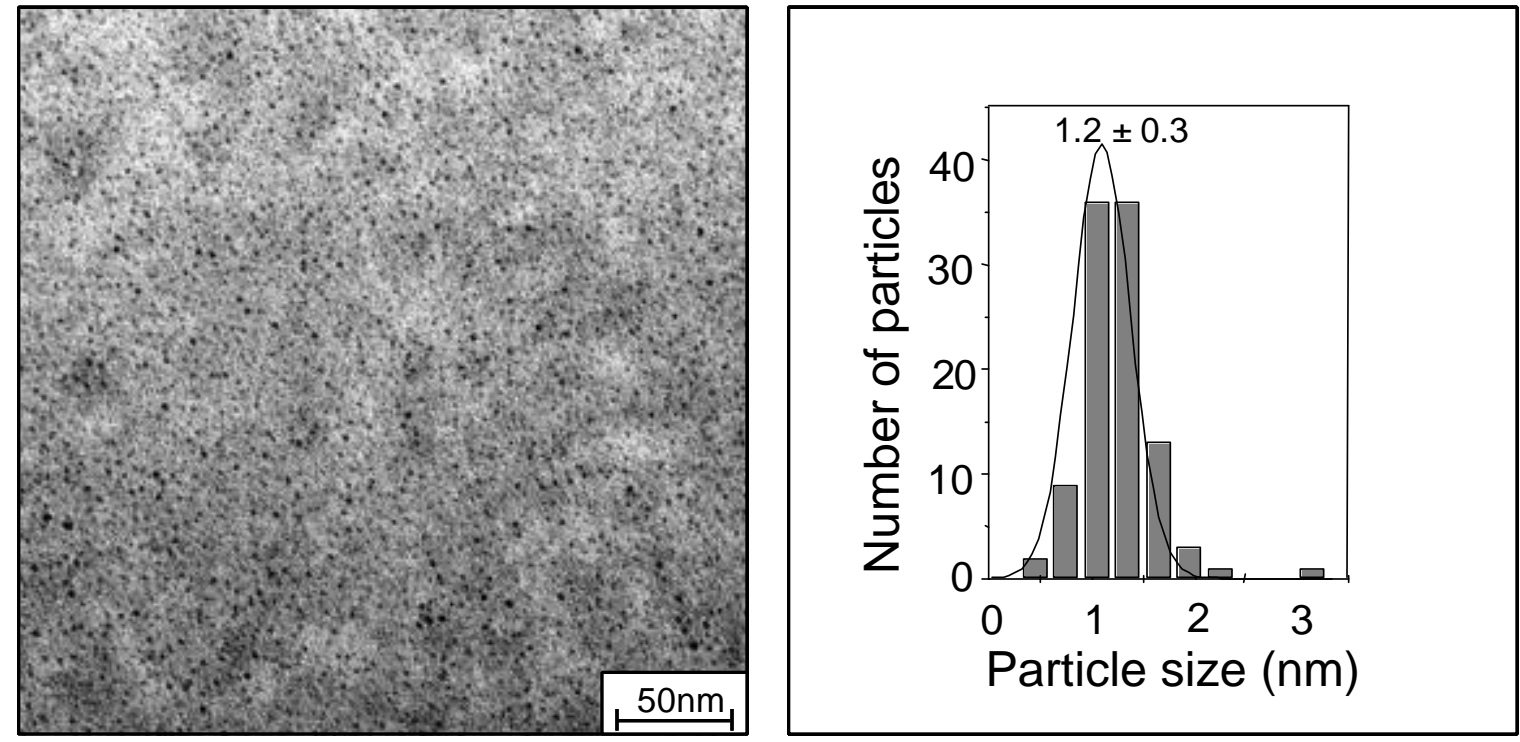

Figure S2. TEM micrograph and histogramm of silver colloid PEIam5K $\mathrm{K}^{\mathrm{lin}} \mathrm{C} 16_{0.5} / \mathrm{Ag}^{\text {coll }}$.
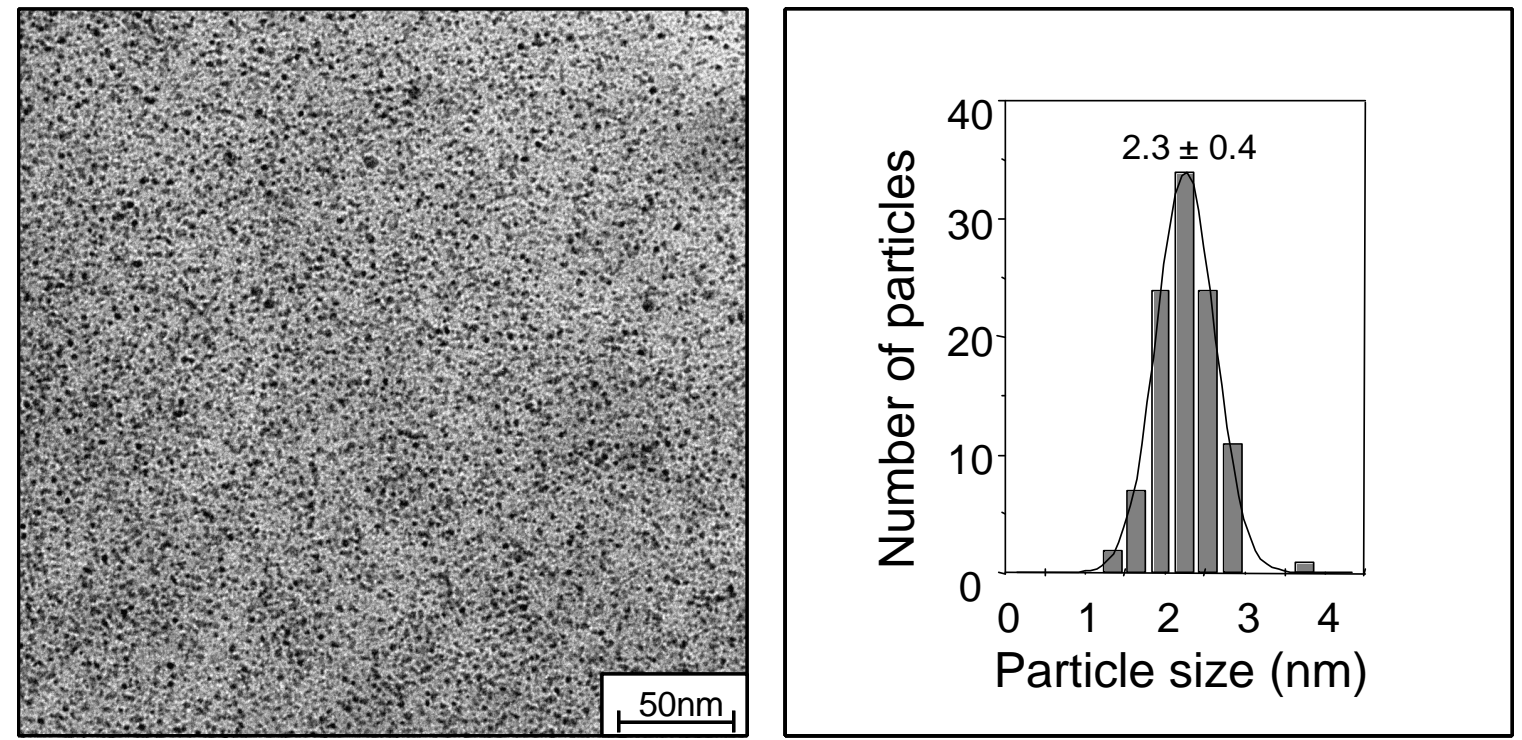

Figure S3. TEM micrograph and histogramm of silver colloid PEIam $25 \mathrm{~K}^{\mathrm{lin}} \mathrm{C} 16_{0.5} / \mathrm{Ag}^{\text {coll }}$. 